\title{
$\widehat{A}$ Madridge \\ madridge Journal of Case Reports and Studies \\ nterconne
}

Case Report

Open Access

\section{Mucoepidermoid Carcinoma of the Lung: A Case Report}

\author{
Asma Navasakulpong \\ Faculty of Internal Medicine, Prince of Songkla University, Hatyai, Songkhla, Thailand
}

\section{Article Info}

*Corresponding author:
Asma Navasakulpong
Department of Internal Medicine
Prince of Songkla University
Hatyai, Songkhla
Thailand
E-mail: navasakulpong@hotmail.com

Received: May 26, 2018

Accepted: June 1, 2018

Published: June 8, 2018

Citation: Navasakulpong A. Mucoepidermoid Carcinoma of the Lung: A Case Report. Madridge J Case Rep Stud. 2018; 2(1): 35-37. doi: 10.18689/mjcrs-1000109

Copyright: @ 2018 The Author(s). This work is licensed under a Creative Commons Attribution 4.0 International License, which permits unrestricted use, distribution, and reproduction in any medium, provided the original work is properly cited.

Published by Madridge Publishers

\begin{abstract}
Introduction: Mucoepidermoid carcinoma (MEC) of the lung is a rare form of lung cancer that is classified into low grade andhigh grade based on histological features. MEC and adenoid cystic carcinoma are considered to be salivary gland-type neoplasms. Surgical resection is the primary treatment for low-grade MEC with excellent outcomes, while high-grade MEC is a more aggressive form of malignancy.
\end{abstract}

\section{Clinical Case}

We reported a case of a 44-year-old woman who was admitted due to spontaneous bacterial peritonitis from alcoholic cirrhosis, Child-Pugh-score of 7 . She was incidentally found left upper lung atelectasis from chest radiograph (CXR). Computerized tomography of the chest revealed an 2 centimeters $(\mathrm{cm})$ enhancing intrapulmonary nodule involved left apicoposterior bronchus with intraluminal extension caused subsegmental atelectasis with fluid filled bronchi distal to lesion. Left paratracheal (4L) and subcarina (7) lymph nodes were enlarged. Endobronchial ultrasound guided transbronchial needle aspiration (EBUSTBNA) was performed at station 7 and $4 \mathrm{~L}$ revealed benign lymphoid tissue. Bronchoscopy with endobronchial biopsy surgical resection, and pathological examination revealed a low-grade MEC with tumor-free margins. No intrathoracic lymph node metastasis.

\section{Conclusion}

Primary pulmonary MEC is a rare type of lung cancer with only few reported cases. This case illustrated a low-grade MEC wherein surgical resection is considered curative. In contrast, high-grade MEC is a more aggressive malignancy with a poorer outcome.

Keywords: Mucoepidermoid Carcinoma; Lung cancer; Surgical resection; Aggressive malignancy.

\section{Background}

Mucoepidermoid carcinoma (MEC) is a rare pulmonary tumor that occurs for 0.1 to $0.2 \%$ of all pulmonary tumors [1]. MECs most often arise from the parotid or submandibular salivary glands. Most pulmonary MECs arise in the proximal bronchi. Histologically, MEC is characterized by a combination of mucus secreting, squamous, and intermediate cell types. Lowgrade MECs are comprised predominantly of glandular elements and mucin-secreting cells, while highgrade MEC consists largely of sheets or nests of squamoid and intermediate cells intermixed with smaller populations of mucus-secreting cells. Pulmonary MEC patients typically present in the third and fourth decade of life and commonly present with symptoms related to bronchial obstruction and atelectasis, such as cough, hemoptysis, wheezing, and post obstructive pneumonia [2]. Complete surgical resection is associated with excellent prognosis. In this report, we describe the case of a 44 year-old woman who incidentally found endobronchial lesion at left upper lobe bronchus which was diagnosed as mucoepidermoid carcinoma of the lung. 


\section{Case Presentation}

A 44-year-old Thai female, who was diagnosed alcoholic cirrhosis, Child-Pugh score of 7 for 2 years, presented with clinical of high grade fever, abdominal pain and abdominal distension. The abdominal paracentesis was performed and diagnosed spontaneous bacterial peritonitis (SBP). She was given intravenous cefotaxime for SBP treatment. During work up for cause of fever, the chest radiograph (CXR) was done and showed left upper lung nodule closed to aortic knob and the decrement of left lung volume which deferred for left upper lobe atelectasis (Figure.1A). She had no history of respiratory symptoms and no history of tuberculosis or tuberculosis exposure. She is non-smoker. Her past medical history was not significant except her liver condition which was treated with low dose spironolactone $50 \mathrm{mg}$ per day. Her family history was noncontributory. Her physical examination was slightly decrease breath sound at left upper lung. Laboratory studies showed leukocytosis of 17,800 cells/ul. Sputum and blood culture were negative. Sputum smear acid fast bacilli for three days were negative. Sputum culture for tuberculosis was negative. Computerized tomography (CT) of the chest was performed and revealed a 2 centimeters enhancing intrapulmonary nodule involved left apicoposterior bronchus with intraluminal extension caused sub segmental atelectasis with fluid filled bronchi distal to lesion (Figure.1B). There were left paratracheal (4L) and subcarina (7) lymph nodes enlargement, 1 and $1.4 \mathrm{~cm}$, respectively (Figure. $2 \mathrm{~A}$ and $\mathrm{B})$. No evidence of metastatic disease was seen.

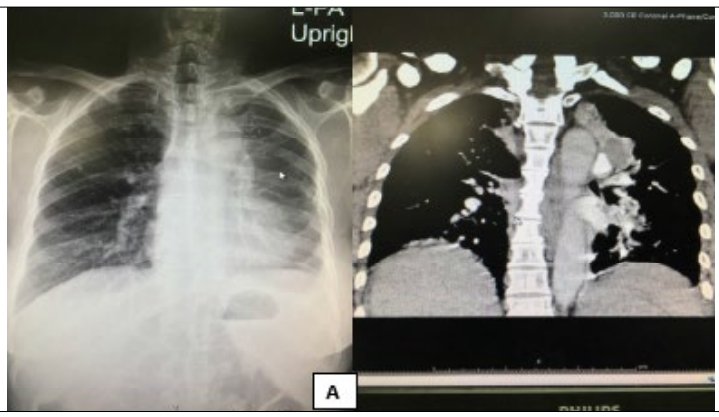

Figureure 1. (A) Chest radiograph frontal view: A left upper lung (LUL) nodule with left upper lung atelectasis (subsegmental). (B) CT chest coronal view: LUL nodule

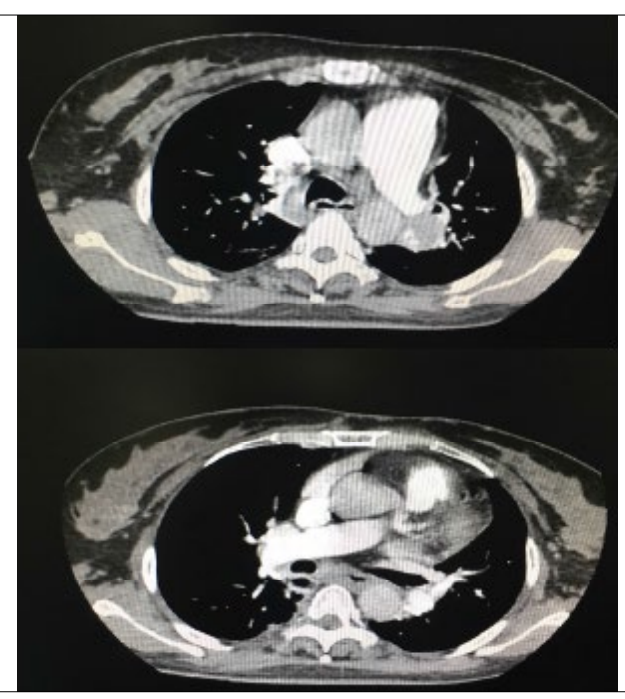

Figureure 2. (A) CT chest cross sectional view: LUL nodule with $4 \mathrm{~L}$ and 7 lymph node enlargement.
Bronchoscopy was performed and demonstrated a smooth, well-circumscribed tumor at the apico posterior segment of left upper lobe orifice, obstructed its lumen. Endobronchial biopsy was performed and revealed low grade mucoepidermoid carcinoma (mucin, CK7, P63 were negative and CK20 and TTF1 were negative). Her spirometry with diffusing capacity of the lung for carbon monoxide (DLCO) was done and showed FEV 1.84 liters (L) (75\%predicted), FVC $2.25 \mathrm{~L}$ (78\% predicted) with DLCO $60 \%$ predicted. After discussed with patient, she agreed to be performed left upper lung lobectomy and mediastinal lymph node dissection. Pathological examination revealed $2.2 \mathrm{~cm}$ tanyellow, well-circumscribed masswithin the bronchial lumen that did not grossly invade into the surrounding lung parenchyma. Microscopic examination showed low grade mucoepidermoid carcinoma without lymphovascular invasion of LUL. (Figure 3A \& B.)

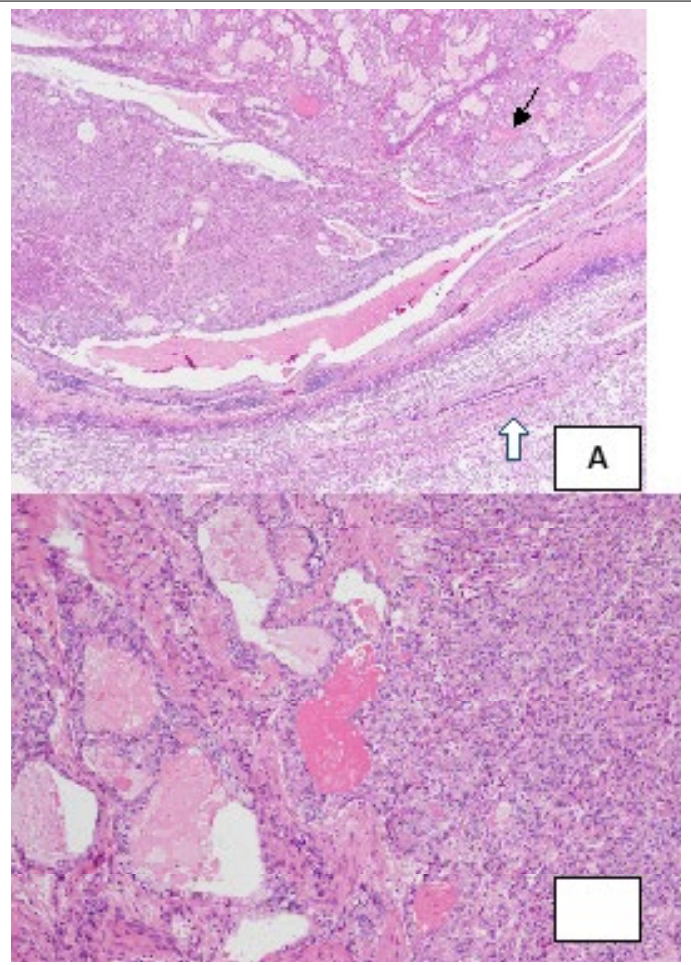

Figureure 3. (A) Low power (40x) microscopic image showing well-demarcated tumor with microcysts (black arrow) and normal lung tissue. (Whitearrow) (B) Higher power (100x) image showing tumor cell admixed with the glandular component and sheets of squamoid cell and no lymphovascular or per neural invasion. The cells lacksignificant mitotic activity, nuclear pleomorphism, and cellular necrosis characteristic of a low-grade mucoepidermoid carcinoma.

Bronchial and vascular margin were free of tumor without intrathoracic lymph nodes metastasis (interlobar, peribronchial, inferior pulmonary ligament, AP window and subcarinal lymph nodes). The patient tolerated surgery well without complication. No adjuvanttreatment was recommended and the patient continues tofollow up with surveillance imaging.

\section{Discussion}

The World Health Organization (WHO) classifies pulmonary MECs as "salivary gland type" tumors along with pulmonaryadenoid cystic carcinomas and epimyoepithelial 
lung carcinoma [3]. There are a few cases of primarypulmonary MEC reported and presented as a mass in trachea, carina or in a mainstem bronchi and occasionally as a peripheral nodule. It is most occurring in younger agegroups as compared to the other more common types of lung cancer and affects males and females equally and the median age of the presentation is 40 years [4]. The commonly presentations are cough, dyspnea, hemoptysis, wheezing and pneumonia. Some cases were asymptomatic. The diagnosis is often delayed due to slow growth, non-specific signs and symptoms and occasionally subtle findingsonthoracic imaging. At bronchoscopy, mucoepidermoid carcinomas may appear as pink, polypoid masses that can be confused with carcinoid tumor. Histologically, MEC is comprised of a mixture ofdifferent cell types including mucin-secreting glandular cells, squamous cells, and intermediate cells. Lowgrade MECis distinguished from highgrade MEC based on the lackof cytological atypia including nuclear pleomorphism andabsence of significant mitotic activity and cellular necrosis. Histological grade is an important prognostic indicator. The ratio of high grade and lowgradevariants is different in the several publications [5]. High-grade MECs demonstrating a greater risk formetastases, tumor recurrence, and death [6]. TNM staging was a significant independent predictor of prognosis in patients with tracheobronchial mucoepidermoid tumors.

While surgical resection remains the standard therapy for patients with pulmonary MEC, different operativeapproaches have been used. Recently, video-assisted thorascopic surgery (VATS) has become the most frequentlyused technique for resection of MECs. Breyer et al. treatedfive patients with MEC with different surgical approachesincluding thoracotomy with conventional lobectomy, sleevelobectomy, and lobectomy, with bronchoplastic closure. No differences in outcome were observed among the various surgical modalities [7]. The goal of surgery is to obtaina complete resection with negative surgical margins. Adjuvant radiotherapy is required in cases of unresectable or incompletely resectable tumors. Patients with low-grade MECs have a generally excellentprognosis with a fiveyear survival rate approaching $95 \%$. In contrast, high grade MECs carry a much poorer prognosis $[8,9]$.

Our patient was a symptomatic case for a lowgrade MEC, a single centrally located well-circumscribedendobronchial tumor without evidence of locoregional ordistant metastasis. The tumor was resected by left upper lobe lobectomy in combination with mediastinal lymph node dissection. Histopathological findings were diagnostic of a lowgrade MEC with a confirmed complete tumor resection withnegative surgical margins and no evidence of metastaticspread to lymph nodes. Based on the experience of multiplegroups in treating low-grade MEC $[2,6,8,9]$ surgical treatment is curative in this group of patients.

\section{Conclusions}

Primary pulmonary MEC represents a rare type of lung cancer. Patients with low-grade MECs, like the patient presentedin this report, generally have a good prognosis after primary surgical resection.

\section{Conflict of Interests}

The author declares that there is no conflict of interests.

\section{Disclosure}

This research received no specific grant from any fundingagency in the public, commercial, or not-for-profit sectors.

\section{References}

1. Leonardi HK, Jung-Legg, Legg YMA, Neptune WB. Tracheobronchial mucoepidermoid carcinoma: Clinicopathological features and results of treatment. Journal of Thoracic and Cardiovascular Surgery. 1978; 76(4): 431-38.

2. Heitmiller RF, Mathisen DJ, Ferry JA, EJ Mark, Grillo HC, et al. Mucoepidermoid lung tumors. Annals of Toracic Surgery. 1989; 47(3): 394-99.

3. Brambilla E, Travis WD, Colby TV, Corrin B, Shimosato Y, et al. The new World Health Organization classificationof lung tumors. European Respiratory Journal. 2001; 18(6): 1059-68. doi: 10.1183/09031936.01.00275301

4. Chopra A, Shim C, Sharma N, Gordon D, Tibb A, et al. Primary salivary type lung tumor: Mucoepidermoid carcinoma. Respiratory Medicine Case Reports. 2013; 9: 18-20.

5. Vadasz P, Egervary M. Mucoepidermoid bronchial tumors: a review of 34 operated cases. European Journal of Cardio-thoracic Surgery. 2000; 9: 56669. doi: 10.1016/S1010-7940(00)00386-9

6. Chin $\mathrm{CH}$, Huang CC, Lin MC, Chao TY, Liu SF, et al. Prognostic factors of tracheobronchial mucoepidermoidcarcinoma-15 years-experience. Respirology. 2008; 13(2): 275-80. doi: 10.1111/j.1440-1843.2007.01207.x

7. Breyer RH, Dainauskas JR, Jensik RJ, Penfeld Faber L, et al. Mucoepidermoid carcinoma of the trachea and bronchus: thecase for conservative resection. Annals of Toracic Surgery. 1980; 29(3): 197-204. doi: 10.1016/ S0003-4975(10)61867-X

8. Leonardi HK, Jung-Legg Y, Legg MA, Neptune WB, et al. Tracheobronchial mucoepidermoid carcinoma. Clinicopathological features and results of treatment. Journal of Toracic and Cardiovascular Surgery. 19787; 6(4): 43138.

9. Ghrairi $H$, Kartas $\mathrm{S}$, Ammar J. Prognosis of mucoepidermoid carcinoma of the bronchi. Revue de Pneumologie Clinique. 2007; 63(1): 29-34. 